\title{
Calculation of the power of thermal energy consumed for heating the reactor of a bioenergy plant
}

\author{
Nodira Imomova ${ }^{1 *}$, Ochil Komilov ${ }^{2}$, Jurabek Majitov ${ }^{2}$, Jukhriddin Ergashov $^{1}$, Kamol \\ Usmonov $^{3}$ \\ ${ }^{1}$ Bukhara branch of the Tashkent Institute of Irrigation and Agricultural Mechanization Engineers, \\ Bukhara, Uzbekistan \\ Bukhara engineering-technological institute, Bukhara, Uzbekistan \\ ${ }^{3}$ Tashkent Institute of Irrigation and Agricultural Mechanization Engineers, Tashkent, Uzbekistan
}

\begin{abstract}
The issues of calculating the power of thermal energy consumed for heating biomass in the reactor of a bioenergy plant are considered. Based on the Fourier heat equation, a solution for the axisymmetric cylindrical problem under boundary conditions of the first kind is obtained, and the power of additional heat sources in a cylindrical biogas reactor is calculated. The influence of the height of the bioreactor and the temperature difference of the biomass on the power consumption of an additional source of thermal energy is analyzed
\end{abstract}

\section{Introduction}

Statement of the problem. The depletion of natural energy resources(oil, natural gas, coal) is currently acute. The extraction of these resources is associated with a high financial cost, the consequence of which is the high price of organic fuel. Another problem associated with the use of traditional energy carriers is environmental (the release of oxides and harmful substances). For this reason, the world is currently paying more and more attention to the use of renewable energy sources [1 - 4]. Biomass is one of the most common sources of energy. The technology of processing biological raw materials has been widely used to solve the problem of environmentally safe disposal of organic waste, reducing environmental pollution, and obtaining alternative energy - biogas and valuable biofertilizers. For biogas production, the most acceptable starting material is waste from animal husbandry, poultry farming, waste from agricultural products and waste from agricultural land, etc. The fermentation makes it possible to produce gaseous fuel (biogas). From the perspective of energy-saving and ecology, the efficient processing of organic waste into biogas is an urgent scientific and technical task [5 - 8].

\footnotetext{
*Corresponding author: shavkat-imomov@rambler.ru
} 


\section{Materials and Methods}

The traditional design of a biogas reactor is an integral tank in which the fermentation process takes place in a single mixing mode, subject to a certain temperature and humidity conditions, depending on the type of fermentation. To optimize the process of processing organic waste to produce biogas, there are three temperature regimes:

1) psychrophilic-up to $20-25^{0} \mathrm{C},[8,9]$.

2) mesophilic $-25-40^{\circ} \mathrm{C},[10,11]$;

3) thermophilic-over $54 \pm 2^{0} \mathrm{C}[8-12]$.

The psychrophilic mode does not require additional heating and passes without additional temperature control, is used in the appropriate climatic zones, with an average annual temperature of at least $18-20^{\circ} \mathrm{C}$. Mesophilic and thermophilic processes require an external heat source and strict temperature control. At the same time, the higher the temperature, the faster and with greater productivity is the formation of biogas. Therefore, in practice, mainly in demand mode bacteriological mesophilic biogas production, since the maximum amount of methane results, there is a fertilizer with a high content of nitrogen. The requirements for the permissible limits of temperature fluctuations for optimal gas formation are the more stringent, the higher the temperature of the fermentation process: at a psychrophilic temperature regime - $\pm 2 \circ \mathrm{C}$ per hour; mesophilic - $\pm 1 \circ \mathrm{C}$ per hour; thermophilic - $\pm 0.5 \circ \mathrm{C}$ per hour [13 - 17]. To obtain the temperature necessary for the fermentation process and, if possible, to maintain it constantly, it is necessary, first of all, to heat the substrate supplied to the reactor to the desired temperature; also constant, bringing heat to compensate for heat losses [18 - 22].

\section{Results and Discussion}

In practice, in many bioreactors, the heat source used to maintain the temperature of the biomass in a certain mode is placed inside it.

Therefore, when analyzing the heat transfer processes in a bioreactor, it is very important to choose the power of additional heat sources, which ensures a uniform and continuous flow of the fermentation process. Therefore, this work aims to develop a method for calculating the power of additional sources of thermal energy based on the Fourier equation of thermal conductivity.

The power of additional heat sources can be calculated based on solving the Fourier heat equation [6 - 10].

In the first approximation, the physical design model of a biogas reactor can be represented by a cylinder of radius $\mathrm{R}$ and height $\mathrm{H}$, and to calculate the temperature; we can assume an axisymmetric distribution of the temperature field, when the temperature inside the reactor depends only on the coordinate R, i.e., consider a one-dimensional problem.

The distribution of the temperature field is determined by the general Fourier heat equation

$$
\frac{\partial T(\tau, r)}{\partial \tau}=a \nabla T(\tau, r)+\frac{q(r)}{\rho c}
$$

where a, p,c are, respectively, the thermal conductivity, density, and heat capacity of the material; $\mathrm{q} I$ is the power of internal heat sources; $\nabla \mathrm{T}(\tau, \mathrm{r})$ is the Laplace operator, in the case of an axisymmetric distribution of the temperature field

$$
\nabla T(r)=\frac{1}{r} \frac{\partial}{\partial r}\left(r \frac{\partial T(r)}{\partial r}\right)
$$


For the steady state (stationary case), equation (1) takes the form

$$
\nabla T(r)=-\frac{q(r)}{\lambda}
$$

where $\lambda$ is the thermal conductivity of the material.

We will also assume that the object is isotropic, i.e., the thermophysical parameters are constant and uniform over the entire volume occupied by them.

The boundary conditions on the inner surface $r=R$ are defined as boundary conditions of the first kind

$$
|T(r)|_{\mathrm{r}=\mathrm{R}}=\mathrm{T}_{0}
$$

The solution of equation (3) is the function

$$
T(r)=g(r)+A P(r)+B
$$

where A, B are constant coefficients determined by the boundary conditions,

$$
\begin{gathered}
\mathrm{P}(\mathrm{r})=\ln r, \\
g(r)=-\int \frac{\partial r}{r} \int r \frac{q(r)}{\lambda} d r
\end{gathered}
$$

for heat sources independent of the spatial coordinate $r$ (uniformly distributed over the volume),

$q(r)=q$, a function defined by the integral (7) has the form

$$
\mathrm{g}(\mathrm{r})=-\frac{q}{4 \lambda} r^{2}
$$

Taking into account the boundedness of the solution at $\mathrm{r}=0$, we should assume $\mathrm{A}=0$. Then, for the temperature field (5), taking into account (8), we obtain

$$
\mathrm{T}(\mathrm{r})=-\frac{q}{4 \lambda} r^{2}+B
$$

The value of the coefficient $\mathrm{B}$ is determined from the condition (4)

$$
\mathrm{B}=\frac{q}{4 \lambda} R^{2}+T_{0}
$$

From expressions (9) and (10), we obtain the distribution of the temperature field in the object

$$
\mathrm{T}(\mathrm{r})=-\frac{q}{4 \lambda}\left(R^{2}-r^{2}\right)+T_{0}
$$

The recommendations for the temperature regimes of biomass fermentation usually indicate the recommended temperature or temperature range, for example, for the mesophilic temperature regime- $34-37^{\circ} \mathrm{C}$. In this case, the temperature range in the first approximation can be taken as the values of the temperature field at the walls of the reactor $T(R)$ and at the center of the reactor $T(0)$. Then to maintain the temperature range

$\mathrm{DT}=\mathrm{T}(0)-\mathrm{T}(\mathrm{R})$ from expression (11) we get

$$
\Delta \mathrm{T}=T(0)-\mathrm{T}(\mathrm{R})=T(0)-T_{0}=\frac{q}{4 \lambda} R^{2}
$$


The power of additional (internal) heat sources is determined by the expression

$$
q=4 \lambda \Delta \mathrm{T} / R^{2}
$$

Taking into account the assumptions that the power of the sources $\mathrm{P}$ is distributed over the entire volume of the reactor $\mathrm{V}$, then for $\mathrm{q}$ we get

$$
q=\frac{P}{V}=4 \lambda \Delta \mathrm{T} / R^{2}
$$

The volume of the cylindrical reactor is equal to

$$
V=\pi R^{2} H
$$

where $\mathrm{H}$ is the height of the reactor.

Finally, taking into account (14) and (15), we obtain an expression for calculating the thermal power of the sources $P$.

$$
\mathrm{P}=4 \pi \lambda \mathrm{H} \Delta \mathrm{T}
$$

It follows from expression (16) that the power of evenly distributed additional heat sources required to maintain the temperature difference DT between the wall and the center of the reactor depends on the height of the reactor $\mathrm{H}$ and the thermal conductivity of the biomass $\lambda$ and does not depend on its radius $\mathrm{R}$.

Figure 1 shows the calculated values of the power of the heat source depending on the height of the reactor $\mathrm{H}$ at different values of DT for biomass with thermal conductivity $\lambda=$ $0.6 \mathrm{~W} /(\mathrm{mK})$.

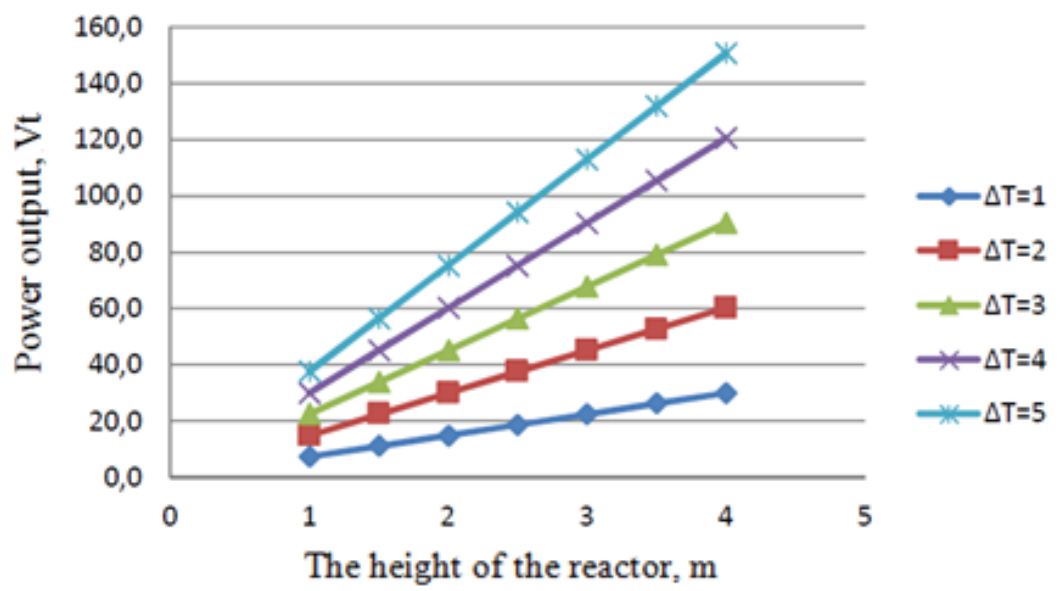

Fig. 1. Calculated values of the heat source power as a function of the reactor height

In conclusion, we note that the obtained expression (16) allows us to estimate the thermal power of additional heat sources evenly distributed over the volume for heating biomass in a cylindrical biogas reactor [19 - 22].

This differs from the mathematical model of Kolosov N. V. [23] obtained in 2019 in the analysis of heat exchange processes in the methane tank of a biogas plant, which allows for correcting the intensity of heat and mass transfer and when the outside air temperature 
changes and deposits form on the outer surface of the heating coil, the mathematical model of heat and mass transfer processes in the absence of mechanical mixing.

\section{Conclusion}

1. In our experiments, a diagram of a heat exchanger operating in the mode of reciprocating phase motion with pulsating loading and unloading of liquid organic waste is presented. To calculate the proposed heat exchanger of biogas plants and solve the problem of optimizing the heat recovery process, we have developed a mathematical model of the process.

2. This allowed us to theoretically take into account the influence of the process parameters during the reciprocating movement of liquid organic waste on heat transfer, the conditions of which differ significantly from the conditions of heat exchange in traditionally used devices. In this regard, it became necessary to develop a special mathematical model of the heat transfer process in the design under consideration, taking into account the nonstationary nature of the process.

\section{References}

1. Trahanova I. A. G. R. Khalitova, Garayev V. the efficiency of the anaerobic digestion process under different regimes of hydraulic mixing, Alternative energy and ecology. (10). p. 90-94. (2011).

2. Sadchikov A. V. Kokarev N. F. Optimization of the thermal regime in biogas plants, Fundamental research. (2-1). pp. 90-93. (2016).

3. Vendin S. V., Mamontov A. Yu. Substantiation of the parameters of thermoregulation and mixing during anaerobic fermentation. Selsky mechanizator. (7). pp. 20-22. (2016).

4. Vendin S. V., Mamontov A. Yu. Automation of mechanical and thermal processes in a multi-chamber biogas reactor of continuous loading of raw materials, Bulletin of the Federal State Educational Institution of Higher Professional Education V. P. Goryachkin Moscow State Agroengineering University. 4 (74). pp. 55-60. (2016).

5. Kartashov E. M. Analytical methods in the theory of thermal conductivity of solids, Textbook. Manual. Ed. 3rd, reprint. And add. M.: Higher School, p 550. (2001).

6. Vendin S.V. Calculation of nonstationary heat conduction in multilayer objects with boundary conditions of the third kind, Journal of Engineering Physics and Thermo physics. 65. (2). p. 823. (1993).

7. Imomov, S. Z. Engineering design calculation of a biogas unit recuperator. Applied Solar Energy (English Translation of Geliotekhnika), 43 (3), pp 196-197. https://doi.org/10.3103/ S0003701X07030188. (2007).

8. Imomov, S., Sultonov, M., Aynakulov, S., Usmonov, K., and Khafizov, O. Mathematical Model of the Processes of Step-By-Step Processing of Organic Waste. In International Conference on Information Science and Communications Technologies: Applications, Trends and Opportunities, ICISCT 2019. Institute of Electrical and Electronics Inc. https://doi.org/10.1109/ICISCT47635.2019.9011929. (2019).

9. Imomov, S. Z. Heat transfer process during phase back-and-forth motion with biomass pulse loading. Applied Solar Energy (English Translation of Geliotekhnika), 45 (2), pp 116-119. https://doi.org/10.3103/S0003701X09020121. (2009). 
10. Marupov, I., Imomov, S., Ermatova, D., Majitov, J., Kholikova, N., Tagaev, V., Nuritov, I. Research of vertical forces for acting tractor unit (2020) IOP Conference Series: Earth and Environmental Science, 614), (2020).

11. Zh. A. Mazhitov. The analysis of energy system costs of recycling methane fermentation, Fan VA texnologiyalar tracciati. Ilmi - technikai magazine. Bukhoro2020. (5). pp 83-87. (2020).

12. Imomov, S., Shodiev, E., Tagaev, V., Qayumov, T. Economic and statistical methods of frequency maintenance of biogas plants (2020) IOP Conference Series: Materials Science and Engineering, 883 (1). (2020)

13. Majitov J.A, Komilov O. S, Sharipov M.Z, Nazarova N. M, Raupova I. B. Bioenergy plant for clematic zones of the Republic of Uzbekistan with a solar heating system for individual use. European Journal of Molecular \& Clinical Medicine ISSN 2515-8260. 07, (02), 2020. pp.6321-6327.https://ejmcm.com/article_3746.html. (2020).

14. I. Marupov., Sh Imomov., D Ermatova., J Majitov., N Kholikova1., V Tagaev., and I Nuritov., Research of vertical forces for acting tractor unit. IOP Conf. Series: Earth and Environmental Science 614 012153, (2020),

15. Mandy Gerber, An analysis of available mathematical models of anaerobic digestion of organic substances for production of biogas, Roland Span, International Gas Union Research Conference Paris, p. 30. (2008).

16. Harun, Zuraini Hassan, Norazwina Zainol, Wan Hanisah, Wan Ibrahim, Haslenda Hashim, Anaerobic Digestion Process of Food Waste for Biogas Production: A Simulation Approach [Текст], Noorlisa, Chemical Engineering and Industrial. 2019. 42, №9. pp. 1834-1839. (2019).

17. Karakashev, D. D.J. Bastone, I, Angelidaki. Influence of environmental conditions on methanogenic compositions in anaerobic biogas reactors, Appl Environ Microbiol. 2005. 71 (1). p. 331-338. (2005)

18. Amon, T. Methane production through anaerobic digestion of various energy crop grown in sustainable crop rotations. Amon T., Amon B., Kryvoruchko V., Machmüller A., Hopfner-Sixt K., Boriroza V., Hrbek R,, Priedel J., Pötsch E., Wagentristel H, Schreiner M., Zollitsch W. // Bioresour Technol. 2007. 98. (17). pp. 3204-3212. (2007)

19. Hill, D. T. A Comprehensive Dynamic Model for Animal Waste Methanogenesis. Transactions of the ASAE. Pp 1374- 1380. (1982),

20. Kaparaju, P., Buendia, I., Ellegaard, L., and Angelidaki, I.,. Effects of mixing on methane production during thermophilic anaerobic digestion of manure, Lab-scale and pilot-scale studies. Bioresource technology. 99 pp 4919-4928. (2007)

21. Rojas C., Fang S., Uhlenhut F., Borchert A., Stein I., Schlaak M. Stirring and biomass starter influences the anaerobic digestion of different substrates for biogas production. Eng. Life Sci;10, pp 339-347. (2010).

22. Biogazanlages: Reizvolle Aufgable fur Yngeneiure. Gobel W, Schweizeriche Zeitschrift, -2012, 4, pp 4 - 7. (2012)

23. L A Sharipov, Sh J Imomov, J A Majitov, O S Komilov, M Z Sharipov, F. Pulatova, S Abdisamatov. Modeling of heat exchange processes in the Metanetka bioenergy plant for individual use, Series: Earth and Environmental Science 614 012035. pp. 183-189, (2020). 